\title{
Migration and Development at Home: Evidence from Albania
}

\author{
Phd Cand. Florenca Gjorduni \\ University of Bari "Aldo Moro", Albania
}

\begin{abstract}
The scientific debate on the phenomenon of return migration and its potential for the development of the economy of the country of origin has attracted the attention of scholars from around the world. Return migration analysis should definitely focus not only on labor migrants but also on student migrants, asylum seekers and refugees. As their characteristics are different, the motives of migration are different, their potential for the development of the country of origin will be different as long as the returnees constitute a group of extremely heterogeneous actors. Liberalization of markets, freedom of mobility supported by the liberalization of state policies, cheaper transportation costs, development of technology and communication have seeded the strengthening of cross-border connections intensifying not only the mobility of people but also the opportunity to be well informed about their return.

Given the importance of this phenomenon in this paper we will focus on the process of return migration to Albania focusing on the role that emigrants have in the development of the country's economy.

The data used for our analysis are taken from the 2013 Migration and Return Integration Survey conducted by the Albanian Institute of Statistics (INSTAT) in cooperation with the Office of the International Organization for Migration (IOM). The main empirical evidence shows that the experience of returning to Albania, the difficulties to reintegrate, to find work, the lack of support from Albanian institutions make Albania, as Russell calls it in his works, "a real laboratory for the study of migration and development". Analyzing the return of Albanians after the financial crisis and re-migration in the coming years, we understand why for Albania the abandonment of the country continues to be an open wound.
\end{abstract}

Keywords: return migration, international migration, human capital, remittances, economic performance 